\title{
An improved micropropagation protocol for the ex situ conservation of Mitragyna parvifolia (Roxb.) Korth. (Rubiaceae): an endangered tree of pharmaceutical importance
}

\author{
Ashok Kumar Patel ${ }^{1}$ (D) Deepika Lodha ${ }^{1} \cdot$ Narpat S. Shekhawat ${ }^{1}$ \\ Received: 26 April 2020 / Accepted: 14 May 2020 / Published online: 22 June 2020 / Editor: Barbara Reed \\ (C) The Society for In Vitro Biology 2020
}

\begin{abstract}
Mitragyna parvifolia (Roxb.) Korth., commonly known as "Kadam," is an endangered and pharmaceutically valued tree of the family Rubiaceae. The numerous medicinal properties are attributed to the various alkaloids of this plant. Poor seedling survival (due to very small size of seeds, approximately 10,000 per gm), overexploitation and habitat destruction are the major constraints in conserving the wild stocks of this species. This paper reports a significant, improved, and repeatable micropropagation protocol of M. parvifolia using nodal explants of a mature tree. Nodal explants harvested during spring season from the lopped tree differentiated the maximum number of axillary shoots (5.3 \pm 0.82 per node) on full-strength Murashige and Skoog (MS) medium containing $3.0 \mathrm{mg} \mathrm{L}^{-1}$ 6-benzylaminopurine (BAP) and additives $\left(25 \mathrm{mg} \mathrm{L}^{-1}\right.$ each of adenine sulfate, L-arginine, and citric acid and $50 \mathrm{mg} \mathrm{L}^{-1}$ ascorbic acid). Shoots were amplified in vitro through (1) recurrent transfer of mother explants and (2) subculturing on fresh nutrient medium. The greatest number of shoots $(13.4 \pm 1.26)$ with an average length of $6.2 \pm 1.03 \mathrm{~cm}$ was produced after $4 \mathrm{wk}$ on MS medium containing $0.5 \mathrm{mg} \mathrm{L}^{-1} \mathrm{BAP}, 0.25 \mathrm{mg} \mathrm{L}^{-1}$ kinetin (Kin), $0.1 \mathrm{mg} \mathrm{L}^{-1}$ Indole-3-acetic acid (IAA), additives, $100 \mathrm{mg} \mathrm{L}^{-1}$ activated charcoal (AC), and $0.8 \%(\mathrm{w} / \mathrm{v})$ agar. This is the first report of concurrent ex vitro rooting and acclimatization (CEVRA) in M. parvifolia. About $90 \%$ micropropagated shoots rooted ex vitro on pulse treatment of $500 \mathrm{mg} \mathrm{L}^{-1}$ Indole-3-butyric acid (IBA; for $5 \mathrm{~min}$ ) and produced $8.5 \pm 0.97$ roots per shoot with an average length of $9.40 \pm$ $1.06 \mathrm{~cm}$, after $5 \mathrm{wk}$. Over $80 \%$ of CEVRA plantlets were successfully transplanted to the soil in field. The defined protocol can be employed for conservation ex situ and restoration/rehabilitation/reintroduction in situ of M. parvifolia.
\end{abstract}

Keywords Endangered tree $\cdot$ Ex situ conservation $\cdot$ Ex vitro rooting $\cdot$ Micropropagation $\cdot$ Mitragyna parvifolia

\section{Introduction}

The genus Mitragyna (Rubiaceae, the coffee family) consists of ten species which are mainly distributed in tropical and arid/ semi-arid parts of Africa, India, China, Bangladesh, Myanmar, Sri Lanka, and south-east Asia (Govaerts et al. 2015). Most of

This paper is dedicated to the frontline workers of COVID-19 Pandemic.

Electronic supplementary material The online version of this article (https://doi.org/10.1007/s11627-020-10089-6) contains supplementary material, which is available to authorized users.

Ashok Kumar Patel

ashpate147@gmail.com

1 Biotechnology Unit, Department of Botany, UGC - Centre of Advanced Study (CAS), Jai Narain Vyas University, Jodhpur, Rajasthan 342 001, India these species exhibit various therapeutic properties and have been used in local/traditional medicines for a number of ailments (Pandey et al. 2006). Leaves of Mitragyna speciosa (Korth.) Havil. are ethno-medicinally used as a substitute for opium (from a non-opium source) or in treatment for opium addiction in many countries; and its demand continues to increase in the western world (Brown et al. 2017). A significant contribution towards the alkaloidal pattern/chemotaxonomic studies of Mitragyna genus was reported by Shellard and his co-workers (Shellard et al. 1969; Shellard and Houghton 1971). Recently, many researchers have extensively reviewed botanical, phytochemical, ethnomedicinal, pharmacological, and toxicological aspects of this genus (Hassan et al. 2013; Raffa 2015; Brown et al. 2017). However, the literature revealed few studies on in vitro regeneration/cultures of Mitragyna species (Roy et al. 1988) with most concentrated on M. speciosa (Phongprueksapattana et al. 2008; Zuldin et al. 2013). 
Mitragyna parvifolia (Roxb.) Korth. (Fig. 1a), known as "Kadam" in Hindi (Bhandari 1995), is distributed from Indian subcontinent to Myanmar (Catalogue of Life 2020). Kadam is well recognized for its innumerable medicinal properties and is widely used by the ayurvedic practitioners. The numerous medicinal properties are probably attributed to the presence of indole and oxindole alkaloids (Brown et al. 2017). The indole alkaloids recognized are akuammigine, ciliaphylline, hirsutine, rhynchociline, and tetrahydroalstonine (Shellard and Houghton 1971; Shellard and Lala 1977). The oxindole alkaloids are 16, 17-dihydro-17b-hydroxy isomitraphylline, 16, 17-dihydro-17b-hydroxy mitraphylline, isomitraphylline, mitraphylline, pteropodine, isopteropodine, speciophylline, and uncarine F (Shellard et al. 1969; Pandey et al. 2006). M. parvifolia is commercially important in timber and paper industry (Chatterjee et al. 1982). Wood quality of Kadam is equal to that of teak and therefore used in making furniture, agricultural appliances, and construction materials; bark yields cordage fibers (The wealth of India 1998). This plant flowers (Fig. 1b) and produces fruits (Fig. 1c) during the months of June to August (Bhandari 1995).

In nature, $M$. parvifolia propagates through its very small seeds (approximately 10,000 per gm), and germinated seedlings are delicate and often wash away with heavy rain or excess water (Roy et al. 1988). Middleton (2009) reported downfall in the population of M. parvifolia at Keoladeo National Park (KNP), Bharatpur, India (a United Nations Educational, Scientific, and Cultural Organization (UNESCO) World Heritage Site and a Ramsar site under the Convention on Wetlands of International Importance, and a managed wetland of ecological significance). UNESCO IUCN Enhancing Our Heritage Project (2003) in a report stated that KNP is possibly the only natural wetland site in the Yamuna River's floodplains where naturally growing
Fig. 1. Mitragyna parvifolia (Roxb.) Korth. (a) Habit. (b) An inflorescence. (c) Fruiting stage.
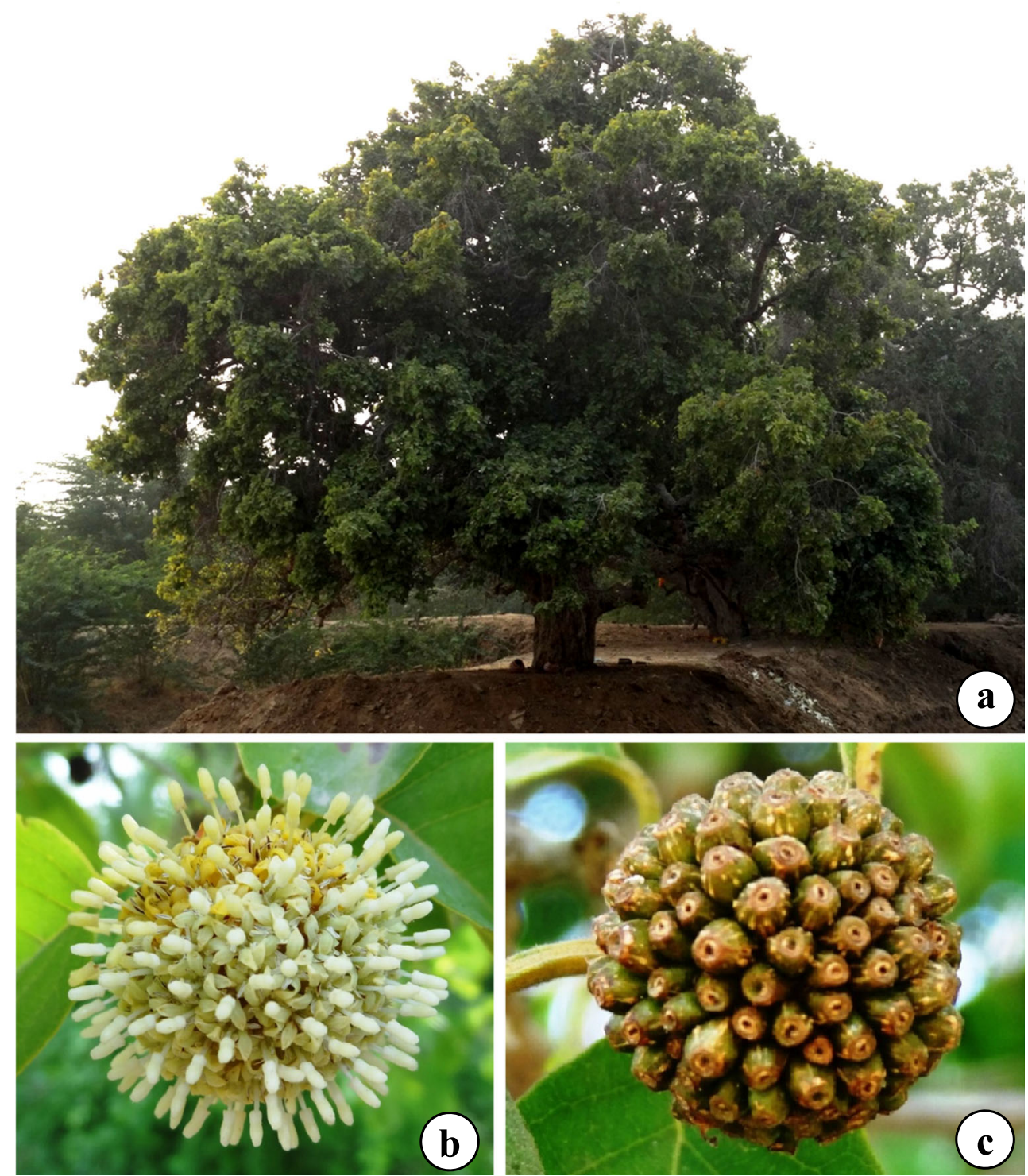
M. parvifolia trees flourished. Moreover, other constraints such as frequent droughts, herbivory, and inter- and intraspecific competition between species are causes of dwindling population of M. parvifolia (Bidalia et al. 2017). Therefore, both in situ and ex situ studies are essential to understand the deterioration of Kadam populations in its natural habitats.

The innumerable pharmaceutical/commercial importance, overexploitation, and habitat destruction has resulted this plant to be categorized as an endangered tree species of Rajasthan (Panwar and Tarafdar 2006; Rai and Lalramnghinglova 2011); though, this species is also facing threat of extinction in its natural habitat (Bidalia et al. 2017). Furthermore, conventional methods of propagation such as rooting of stem cutting, grafting, and layering were unsuccessful for this slow growing species (Roy et al. 1988). Consequently, there is an immediate need to conserve the wild stocks as well as to multiply/propagate this plant species through alternative approaches. Therefore, micropropagation technology can be efficiently employed for the large-scale multiplication/propagation of $M$. parvifolia in a short span of time. Also, micropropagation as an "integrated plant conservation" strategy can combine in situ as well as ex situ approaches to ensure conservation of threatened plant taxa (Werden et al. 2020). Earlier, an attempt has been made to propagate this plant through tissue culture (Roy et al. 1988), but there was a need to refine/improve upon the existing protocol. Therefore, the present work was done to develop a significantly improved micropropagation protocol using nodal explants obtained from a mature tree for sustainable propagation and ex situ conservation of M. parvifolia. In order to reduce the cost, time, labor, and resources for the protocol, conditions for concurrent ex vitro rooting and acclimatization (CEVRA) have been optimized for the first time in M. parvifolia. The preliminary data of this work has been published as an abstract in 2016 World Congress on In Vitro Biology (Patel et al. 2016a), and the complete experimental data are presented here in this manuscript.

\section{Materials and Methods}

Explant preparation and surface sterilization A Mitragyna parvifolia (Roxb.) Korth. plant, more than 40-yr-old, growing in the garden of Department of Botany, Jai Narain Vyas University, Jodhpur, was used as the source plant for micropropagation. The old branches of the mother plant were removed (lopped) during the preceding winter (Dec to Jan) season. Fresh sprouts of following spring (Feb to Mar), summer (May to Jun), autumn (Sept to Oct), and winter (Dec to Jan) seasons were used as explants to study the influence of different seasons on culture establishment. Nodal segments (4 to $5 \mathrm{~cm}$ long) with one node each were washed thoroughly and surface sterilized using mercuric chloride $\left(0.1 \% \mathrm{HgCl}_{2}(\mathrm{w} / \mathrm{v})\right)$ for 4 to $5 \mathrm{~min}$, followed by 5 to 6 washing with autoclaved tap water under a laminar air flow hood. The surface sterilized explants were kept in a sterile pre-chilled antioxidant solution (ascorbic acid and citric acid $0.1 \%(\mathrm{w} / \mathrm{v})$ ) for 18 to $20 \mathrm{~min}$ prior to inoculation.

Culture medium and incubation conditions The surface sterilized and antioxidant-treated nodal segments were inoculated vertically on Murashige and Skoog (MS; 1962) medium supplemented with $1.0,2.0,3.0$, or $4.0 \mathrm{mg} \mathrm{L}^{-1} \mathrm{BAP}$ or Kin (HiMedia ${ }^{\circledR}$, Mumbai, India) for axillary shoot bud induction. Influence of $25 \mathrm{mg} \mathrm{L}^{-1}$ each of adenine sulfate, L-arginine, and citric acid and $50 \mathrm{mg} \mathrm{L}^{-1}$ ascorbic acid (all additives were procured from HiMedia ${ }^{\circledR}$, India) on shoot growth and development were studied. Also, the effect of MS, $1 / 2$ MS, WP (Lloyd and McCown 1981), or $1 / 2$ WP on bud-breaking/shoot bud induction were optimized. The WP and MS media contained 2.0 and $3.0 \%(\mathrm{w} / \mathrm{v})$ sucrose, respectively, and solidified with $0.8 \%(\mathrm{w} / \mathrm{v})$ agar (Qualigens Fine Chemicals, Mumbai, India). The $\mathrm{pH}$ of medium with PGRs was adjusted to $5.8 \pm 0.02$ prior to autoclaving at $1.1 \mathrm{~kg} \mathrm{~cm}^{-2}$ pressure and $121^{\circ} \mathrm{C}$ temperature for 15 to $16 \mathrm{~min}$. The cultures were initially incubated in dark for 2 to $3 \mathrm{~d}$ and thereafter shifted to growth room maintained at temperature $26 \pm 2^{\circ} \mathrm{C}$, photoperiod of 14 to 16-h with a light intensity of 40 to $50 \mu \mathrm{mol} \mathrm{m} \mathrm{s}^{-1}$ photon flux density (PFD) and relative humidity (RH) $60 \pm 2 \%$.

Shoot multiplication and maintenance Shoots were amplified by two methods: (1) recurrent transfer of mother/original explants (after harvesting the first batch of in vitro formed shoots) on fresh nutrient medium containing $\mathrm{BAP}(0.5,1.0$, 1.5 , or $\left.2.0 \mathrm{mg} \mathrm{L}^{-1}\right)$ or IAA $\left(0.05,0.10\right.$, or $\left.0.20 \mathrm{mg} \mathrm{L}^{-1}\right)$ for 4 wk and up to 4 subsequent 4 -wk passages. The effects of successive transfers on shoot multiplication were recorded. To overcome the problem of oxidative browning during recurrent passages, different concentration of activated charcoal (AC; 50,100 , or $200 \mathrm{mg} \mathrm{L}^{-1}$ ) were added to the medium. (2) Subculture of in vitro formed shoots (after decapitating apical shoot-tip and making a clump of 2 to 3 shoots, each 2 to $3 \mathrm{~cm}$ ) on fresh MS medium supplemented with $0.25,0.5$, or $1.0 \mathrm{mg} \mathrm{L}^{-1} \mathrm{BAP}$ or Kin alone or in combinations with 0.05 , 0.10 , or $0.20 \mathrm{mg} \mathrm{L}^{-1}$ IAA. After optimizing the best combination of PGRs, effect of gelling agents $(0.8 \%(\mathrm{w} / \mathrm{v})$ agar, $0.14 \%(\mathrm{w} / \mathrm{v})$ gellan-gum (Sigma-Aldrich ${ }^{\circledR}$, St. Louis, MO) or liquid) on shoot multiplication was evaluated. The shoot cultures were maintained for 2-y by regular subculturing every fourth/fifth week without any change in growth and vigor. During subculturing, sucrose was replaced in the medium with table sugar (Daurala Sugar Cubes, Noida, India).

Concurrent $e x$ vitro rooting and acclimatization For rooting under $e x$ vitro/greenhouse conditions, the shoots $(3$ to $6 \mathrm{~cm}$ ) were individually excised from the multiplied cultures. The 
base ( 2 to $3 \mathrm{~mm}$ ) of shoots was dipped in $100,300,500$, or $700 \mathrm{mg} \mathrm{L}^{-1}$ of freshly prepared aqueous solutions of IBA or NAA for 1, 3,5, or $7 \mathrm{~min}$. These shoots were transferred to the bottles containing sterile soilrite ${ }^{\circledR}$ (a mixture of horticulture grade-expanded perlite, exfoliated vermiculite, and Irish Peat moss in equal ratio; procured from Keltech Energies Limited, Bengaluru, India) and enriched with quarter-strength MS macro-salts. The bottles were surmounted with polycarbonatecaps and placed near the pad section of greenhouse (fitted with cellulose pads that are continuously drenched with water, having high RH (85 to $90 \%)$ and moderate temperature ( $28 \pm$ $\left.2^{\circ} \mathrm{C}\right)$ ). Once root formation was initiated/observed in treated shoots, the bottles were successively moved towards the fan section (fitted with heavy duty exhaust fans, having low RH (45 to $50 \%$ ) and high temperature $\left(36 \pm 2^{\circ} \mathrm{C}\right)$ ) of greenhouse. Meanwhile, polycarbonate-caps of the bottles were also unscrewed over a period of 2 to $3 \mathrm{wk}$ and eventually removed thereafter.

Soil/field transfer of acclimatized plantlets The CEVRA plantlets were transplanted to the earthen pots containing a mixture of sand, garden soil, and farmyard manure (1:1:1) and irrigated with tap water three times a week for next 2 to $3 \mathrm{wk}$ and then transferred to the field.

\section{Experiment design, data collection, and statistics analysis All} the experiments were set up in a completely randomized block design (RBD) with fifteen replicates per treatment and repeated three times. The observations, shoot number/length and root number/length, were recorded over first to fifth week depending on the experiment. Percentage response was calculated using the formula $=$ (total number of responding explants/total number of cultured explants $) \times 100$. The data were analyzed statistically using one-way analysis of variance (ANOVA) and differences amongst the mean values $(P$ $<0.05$ ) were calculated by Duncan's multiple range test (DMRT) using the SPSS (Statistical Package for the Social Sciences) software ver. 17 (IBM, Chicago, IL). All the results are presented in the form of mean $\pm \mathrm{SD}$ of three independent experiments.

\section{Results and Discussion}

Effect of explanting seasons on culture establishment In the present study, culture establishment/response was influenced by the season of explant collection. The explants collected during the spring season (Feb to March) from the selected lopped tree were found the most responsive followed by the explants collected during autumn, summer, and winter seasons, respectively. Similar trends were reported in Salvadora persica (Phulwaria et al. 2011) and S. oleoides (Shekhawat et al. 2012). Explants collected during the spring season were better in terms of percentage bud-breaking response, early bud-breaking, or days to respond and showed the least contamination in this study. Similarly, season-specific culture responses were earlier observed in Tecomella undulata (Chhajer and Kalia 2017) and Tinospora cordifolia (Panwar et al. 2018). Funada et al. (2001) explained that during the spring season, more auxins are synthesized in young buds which trigger cellular division in the cambium and hence assist in enhancing active growth.

Phenolic leaching during culture establishment The problem of phenolic exudation/leaching was observed during culture initiation. To conquer this, sterilized nodal explants were treated with the sterile pre-chilled antioxidant solution (ascorbic acid and citric acid $0.1 \%(\mathrm{w} / \mathrm{v}))$ for 18 to $20 \mathrm{~min}$ prior to inoculation. Similar superficial treatments of ascorbic acid and citric acid were adopted by many researchers in different plants (Phulwaria et al. 2012; Bhojwani and Dantu 2013). Initial incubation in dark for 2 to $3 \mathrm{~d}$ also assisted in reducing phenolic exudation to an extent. Additionally, such initial exposure of explants to dark/diffused light conditions for a certain period can promote morphogenesis by axillary meristem activation as reported by Panwar et al. (2018).

Effect of cytokinins on bud-breaking The nodal segments induced axillary shoot buds on MS medium containing BAP or Kin, within 1 to $2 \mathrm{wk}$. The frequency of bud-breaking varied from 20.7 to $89.4 \%$ on different concentrations of cytokinins tested (Table 1). Of the treatments evaluated, MS containing $3.0 \mathrm{mg} \mathrm{L}^{-1}$ BAP was recorded as the best for bud-breaking on which the maximum number of shoots (approximately 4) was obtained (data not shown). On increasing the concentration of BAP beyond $3.0 \mathrm{mg} \mathrm{L}^{-1}$, moderate callusing, fewer, and vitrified shoots with stunted growth were observed. Explants cultured on MS basal medium (control) did not show any bud-breaking. Similarly, the efficiency of BAP over other cytokinins in axillary shoot bud induction has been well reported in several tree/woody species (Shekhawat and Manokari 2016; Zarei et al. 2020; Machado et al. 2020).

Effect of additives on bud-breaking Incorporation of additives in the BAP-3.0 $\mathrm{mg} \mathrm{L}^{-1}$ optimized MS medium, significantly improved shoot induction $(5.3 \pm 0.82$ per node $)$ and shoot health (Fig. 2a). In additives, adenine sulfate may have complemented the effect of cytokinins owing to its base structural similarity to cytokinins (Chhajer and Kalia 2017). Likewise, addition of $15 \mathrm{mg} \mathrm{L}^{-1}$ adenine sulfate improved multiple shoot formation in Withania somnifera (Sivanandhan et al. 2015). According to Greenwell and Ruter (2018), the molecular structure of arginine $\left(\mathrm{C}_{6} \mathrm{H}_{14} \mathrm{~N}_{4} \mathrm{O}_{2}\right)$ includes two extra nitrogen (imino) groups, and this higher percentage of reduced nitrogen (32.2\%) may have been responsible for the improved shoot elongation 
Table 1. Effect of Murashige and Skoog medium containing 6-benzylaminopurine (BAP) and kinetin (Kin) on bud-breaking from mature nodal explants of Mitragyna parvifolia (Roxb.) Korth. (after 4 wk)

\begin{tabular}{|c|c|c|c|c|}
\hline \multicolumn{2}{|c|}{ Cytokinins $\left(\mathrm{mg} \mathrm{L}^{-1}\right)$} & \multirow[t]{2}{*}{$\%$ explants responded } & \multirow[t]{2}{*}{ Average shoot number $\pm \mathrm{SD}$} & \multirow[t]{2}{*}{ Average shoot length $(\mathrm{cm}) \pm \mathrm{SD}$} \\
\hline BAP & Kin & & & \\
\hline Control & - & $0.0^{\mathrm{g}}$ & $0.0 \pm 0.0^{\mathrm{g}}$ & $0.0 \pm 0.0^{\mathrm{f}}$ \\
\hline 1.0 & - & $57.1^{\mathrm{d}}$ & $1.9 \pm 0.56^{\mathrm{d}}$ & $1.38 \pm 0.29^{\mathrm{d}}$ \\
\hline 2.0 & - & $72.3^{\mathrm{b}}$ & $3.1 \pm 0.73^{\mathrm{c}}$ & $2.41 \pm 0.40^{\mathrm{c}}$ \\
\hline 3.0 & - & $89.4^{\mathrm{a}}$ & $5.3 \pm 0.82^{\mathrm{a}}$ & $3.69 \pm 0.59^{\mathrm{a}}$ \\
\hline 4.0 & - & $75.2^{\mathrm{b}}$ & $3.9 \pm 0.73^{\mathrm{b}}$ & $3.01 \pm 0.41^{\mathrm{b}}$ \\
\hline - & 1.0 & $20.7^{\mathrm{f}}$ & $0.7 \pm 0.23^{\mathrm{f}}$ & $0.84 \pm 0.26^{\mathrm{e}}$ \\
\hline - & 2.0 & $48.2^{\mathrm{e}}$ & $1.3 \pm 0.67^{\mathrm{e}}$ & $0.90 \pm 0.31^{\mathrm{e}}$ \\
\hline - & 3.0 & $63.0^{\mathrm{c}}$ & $2.1 \pm 0.73^{\mathrm{d}}$ & $1.99 \pm 0.41^{\mathrm{c}}$ \\
\hline - & 4.0 & $72.4^{\mathrm{b}}$ & $3.2 \pm 0.78^{\mathrm{c}}$ & $2.98 \pm 0.47^{b}$ \\
\hline
\end{tabular}

Means in each column followed by same letters at superscript are not significantly different according to Duncan's Multiple Range Test at $P<0.05$
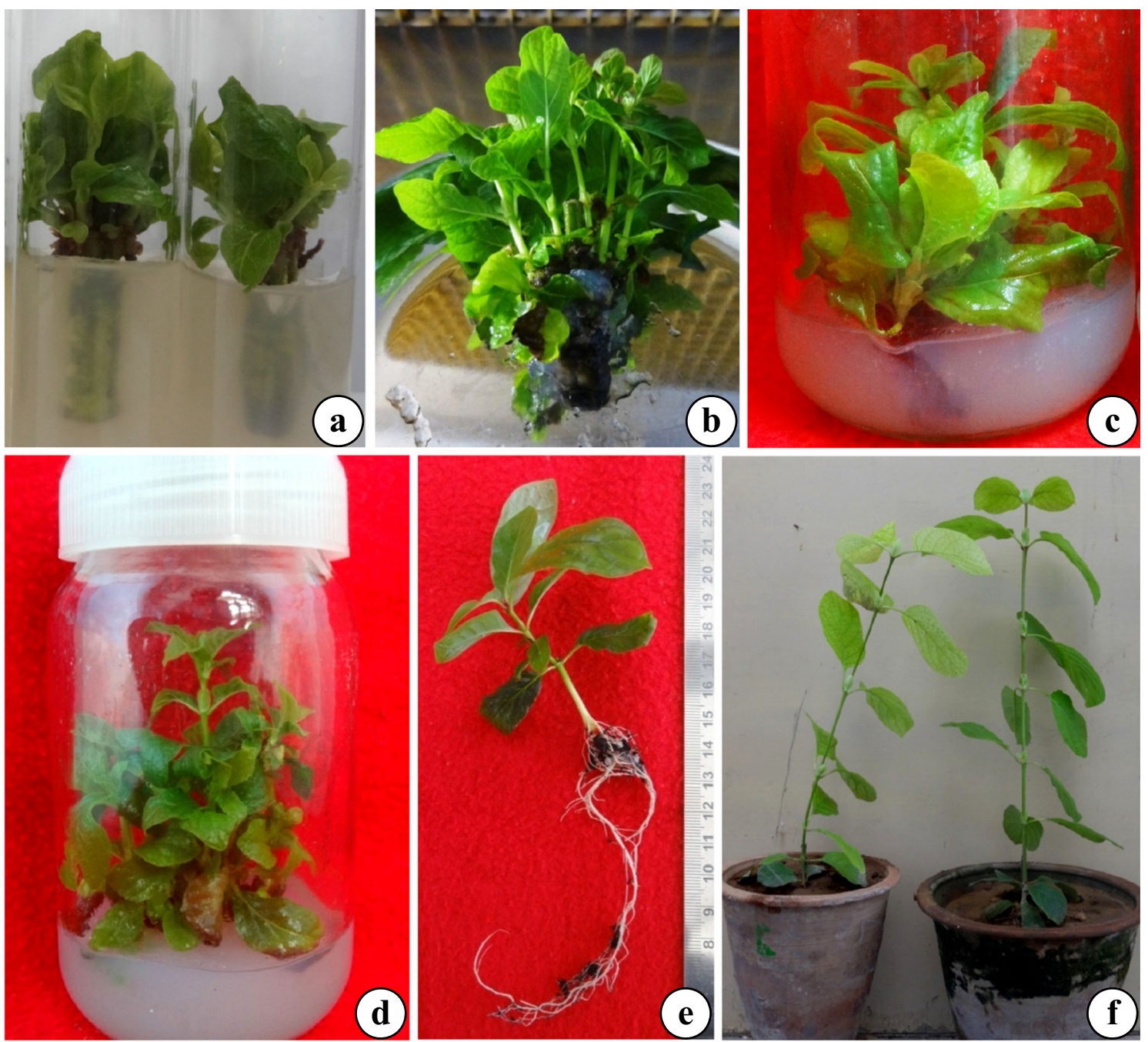

Fig. 2. Micropropagation protocol of Mitragyna parvifolia (Roxb.) Korth. (a) Shoot bud induction on Muraghige and Skoog medium +6benzylaminopurine (BAP; $3.0 \mathrm{mg} \mathrm{L}^{-1}$ ) supplemented with additives (after $4 \mathrm{wk}$ ). (b) Shoot amplification through recurrent transfer of mother explant on MS medium containing BAP $\left(1.0 \mathrm{mg} \mathrm{L}^{-1}\right)$, Indole-3acetic acid (IAA; $0.1 \mathrm{mg} \mathrm{L}^{-1}$ ), additives, and activated charcoal (AC;

amplification through subculturing of in vitro formed shoots on MS medium containing BAP $0.5 \mathrm{mg} \mathrm{L}^{-1}$, kinetin $0.25 \mathrm{mg} \mathrm{L}^{-1}$, IAA $0.1 \mathrm{mg} \mathrm{L}^{-1}$, additives, and AC $100 \mathrm{mg} \mathrm{L}^{-1}$ on $0.8 \%(\mathrm{w} / \mathrm{v})$ agar-gelled medium after $3 \mathrm{wk}$ and $4 \mathrm{wk}$, respectively. (e) Ex vitro rooting in shoots treated with Indole-3-butyric acid (IBA; $500 \mathrm{mg} \mathrm{L}^{-1}$ ) for $5 \mathrm{~min}$ (after $5 \mathrm{wk}$ ). $f$ Hardened plants transferred to earthen pots (after $8 \mathrm{wk}$ ). $100 \mathrm{mg} \mathrm{L}^{-1}$ ) after second passage (after $4 \mathrm{wk}$ ). (c) and (d) Shoot 
( $3.69 \pm 0.59 \mathrm{~cm})$. Similarly, addition of $7.5 \mathrm{mg} \mathrm{L}^{-1} \mathrm{~L}$-arginine facilitated the elongation of shoot buds in Jatropha curcas (Liu et al. 2016). Furthermore, ascorbic acid and citric acid work as antioxidants in the culture medium (Bhojwani and Dantu 2013). The advantageous effects of these additives in improving in vitro growth and development have been recognized in Alhagi maurorum (Agarwal et al. 2015) and Blyttia spiralis (Patel et al. 2016b). Therefore, these additives were regularly added to the forthcoming media.

Effect of media type on bud-breaking Of the type and strength of media evaluated, full-strength MS medium proved to be most suitable for bud-breaking. However, explants responded on all the media types and strengths but percent response, shoot number, and shoot length were less on WP, $1 / 2 \mathrm{MS}$, and $1 / 2$ WP media, respectively. In comparison with MS medium, WP medium contains reduced amounts of nitrates and higher amount of calcium and thiamine, and lacks iodine or cobalt (Lloyd and McCown 1981). The superiority of MS medium over WP medium for tree species has been acknowledged in Salvadora oleoides (Shekhawat et al. 2012), Terminalia bellirica (Phulwaria et al. 2012), and Neolamarkia cadamba (Huang et al. 2020).

\section{Shoot multiplication and maintenance}

\section{(i) Recurrent passage of original/mother explants}

In the first approach for shoot amplification, the original/ mother explants were recurrently cultured on fresh nutrient medium supplemented with cytokinin or cytokinin-auxin combinations, for four passages. Amongst these, MS medium supplemented with $1.0 \mathrm{mg} \mathrm{L}^{-1}$ BAP and $0.1 \mathrm{mg} \mathrm{L}^{-1}$ IAA produced the greatest number of shoots (8.2 per explant) after the second recurrent passage (Fig. $2 b$ ). Although new shoots were formed up to the fourth passage, their multiplication rate decreased with successive passages. Shoot amplification through this approach is a faster, safer, and economic way to regenerate new flush of micro-shoots. This method of shoot amplification has been found successful in a number of tree/ woody species such as Salvadora persica (Phulwaria et al. 2011), S. oleoides (Shekhawat et al. 2012), and Couroupita guianensis (Shekhawat and Manokari 2016).

Effect of activated charcoal Phenolic exudation has been a major concern for in vitro establishment and further growth especially in mature and woody tree species. To overcome this problem during recurrent transfers, $100 \mathrm{mg} \mathrm{L}^{-1} \mathrm{AC}$ was found the best and produced sturdier shoots with well-developed foliage and without any phenolic leaching/oxidative browning. Similarly, beneficial results of AC were also observed in a few reports (Patel et al. 2016b; Zarei et al. 2020). According to Bhojwani and Dantu (2013), AC is added in culture medium to irreversibly adsorb toxic/brown exudates/ metabolites, phenolic inhibitors, and abscisic acid and to help in improving aeration. Additionally, $\mathrm{AC}$ takes part in various stimulatory activities by sustainably releasing its own natural substances, and the adsorbed PGRs and nutrients which ultimately become available to the growing cultures (Thomas 2008). Therefore, AC also became an important constituent of the subculturing media.

\section{(ii) Subculturing of in vitro formed shoots}

In second approach of amplification, in vitro shoots (after making a cluster of 2 to 3 shoots) was subcultured on MS medium containing cytokinin, cytokinin-cytokinin, or cytokinins-auxin combinations. In comparison with 0.25 , 0.5 , or $1.0 \mathrm{mg} \mathrm{L}^{-1} \mathrm{BAP}$ alone, greater numbers of shoots were obtained from cultures grown on medium containing combinations of $\operatorname{BAP}\left(0.25,0.5\right.$, or $\left.1.0 \mathrm{mg} \mathrm{L}^{-1}\right)$ and Kin $(0.25$ or $0.5 \mathrm{mg} \mathrm{L}^{-1}$ ) (Table 2). Similar is the case in Tecomella undulata where a combination of two cytokinins proved beneficial in comparison with a single cytokinin (Chhajer and Kalia 2017). Shoots subcultured on MS basal medium without any PGR failed to respond and turned black/brown within 2 to 3 wk. Amongst the concentration and combination of PGRs evaluated, MS medium containing $0.5 \mathrm{mg} \mathrm{L}^{-1}$ BAP, $0.25 \mathrm{mg} \mathrm{L}^{-1} \mathrm{Kin}$, and $0.1 \mathrm{mg} \mathrm{L}^{-1}$ IAA gave the optimum multiplication response. On this medium, along with additives (25 $\mathrm{mg} \mathrm{L}^{-1}$ each of adenine sulfate, L-arginine, and citric acid and $50 \mathrm{mg} \mathrm{L}^{-1}$ ascorbic acid) and $100 \mathrm{mg} \mathrm{L}^{-1} \mathrm{AC}$, the maximum numbers of shoots (13.4 \pm 1.26$)$ of mean shoot length $6.2 \pm 1.03 \mathrm{~cm}$ was obtained after $4 \mathrm{wk}$ incubation (Fig. $2 c$ and d). In contrast to only BAP- or Kin-supplemented media, greater multiplication rate/response was observed on the medium supplemented with a combination of BAP, Kin, and IAA. In the present study, supplementation of IAA in subculturing medium significantly $(P<0.05)$ enhanced shoot multiplication by fostering axillary branching. A combination of two cytokinins (BAP and Kin) and an auxin (IAA) acted synergistically and positively regulated shoot amplification in this study. This auxin-cytokinin synergism is known to control various significant developmental activities, including the formation and maintenance of meristem that are essential for shoot branching/regeneration (Su et al. 2011). Similar synergism of auxin and cytokinin(s) for efficient shoot amplification has been reported in Salvadora oleoides (Phulwaria et al. 2014), Tinospora cordifolia (Panwar et al. 2018), and Moringa oleifera (Gupta et al. 2020). The replacement of sucrose with table sugar did not affect the multiplication rate/response in this study as evidenced by Chhajer and Kalia (2017).

The shoot number achieved in this study $(13.4 \pm 1.26)$ was significantly greater than 8 to 10 reported by Roy et al. (1988) in the same taxon. The possible reasons behind this increment may be the various modifications that were made during the 
Table 2. Effect of Murashige and Skoog medium containing additives, $100 \mathrm{mg} \mathrm{L}^{-1}$ activated charcoal, and various concentration and combination of PGRs on shoot amplification through subculturing of in vitro-formed shoots of Mitragyna parvifolia (Roxb.) Korth. (after 4 wk)

\begin{tabular}{lllcr}
\hline Concentrations of PGRs $\left(\mathrm{mg} \mathrm{L}^{-1}\right)$ & & Average shoot number \pm SD & Average shoot length (cm) \pm SD \\
\hline BAP & Kin & IAA & & $0.0 \pm 0.0^{\mathrm{g}}$ \\
\hline Control & - & - & $0.0 \pm 0.0^{\mathrm{i}}$ & $3.29 \pm 0.39^{\mathrm{f}}$ \\
0.25 & - & - & $2.1 \pm 0.56^{\mathrm{h}}$ & $3.79 \pm 0.46^{\mathrm{e}}$ \\
0.5 & - & - & $4.2 \pm 0.78^{\mathrm{ef}}$ & $4.69 \pm 0.52^{\mathrm{d}}$ \\
1.0 & - & - & $3.1 \pm 0.73^{\mathrm{g}}$ & $5.19 \pm 0.59^{\mathrm{c}}$ \\
0.5 & 0.25 & - & $7.1 \pm 0.87^{\mathrm{d}}$ & $5.8 \pm 0.67^{\mathrm{ab}}$ \\
0.5 & 0.5 & - & $5.0 \pm 0.81^{\mathrm{e}}$ & $4.19 \pm 0.48^{\mathrm{de}}$ \\
0.5 & 1.0 & - & $3.9 \pm 0.73^{\mathrm{fg}}$ & $5.4 \pm 0.60^{\mathrm{bc}}$ \\
0.5 & 0.25 & 0.05 & $10.1 \pm 0.99^{\mathrm{b}}$ & $6.2 \pm 1.03^{\mathrm{a}}$ \\
0.5 & 0.25 & 0.10 & $13.4 \pm 1.26^{\mathrm{a}}$ & $4.30 \pm 0.52^{\mathrm{d}}$ \\
\hline
\end{tabular}

Means in each column followed by same letters at superscript are not significantly different according to Duncan's Multiple Range Test at $P<0.05$ 6-benzylaminopurine $(B A P)$, kinetin (Kin), and Indole-3-acetic acid (IAA)

culture process over Roy et al. (1988) such as removing branches (lopping) of mother/source plant, season of explant collection, selection of an appropriate combination of PGRs, incorporation of additives, and $\mathrm{AC}$ in the medium.

Effect of gelling agents Of the two gelling agents evaluated, MS medium containing $0.8 \%$ agar $(\mathrm{w} / \mathrm{v})$ was found better in terms of both shoot multiplication and shoot quality. On $0.14 \%$ (w/v) gellan-gum solidified medium, shoot multiplication was significantly lower $(P<0.05)$ and shoots turned to yellow/light green color with excessive rooting at the base of shoot clump. These results are in consonance with Sharma et al. (2011) and Patel et al. (2016b). In this study, liquid medium proved the least effective for shoot multiplication. Agar is the most important and commonly used gelling agent in micropropagation owing to its stability, steadiness, high gel clarity and strength, and resistance to metabolism during culture. According to Ziv (1991), gelling agents may affect the water availability, humidity, headspace composition, and availability of other media components, especially cytokinins, in a sealed container. Therefore, MS medium containing $0.5 \mathrm{mg} \mathrm{L}^{-1}$ BAP, $0.25 \mathrm{mg} \mathrm{L}^{-1} \mathrm{Kin}, 0.1 \mathrm{mg} \mathrm{L}^{-1} \mathrm{IAA}$, $25 \mathrm{mg} \mathrm{L}^{-1}$ adenine sulfate, $25 \mathrm{mg} \mathrm{L}^{-1} \mathrm{~L}$-arginine, $25 \mathrm{mg} \mathrm{L}^{-1}$ citric acid, $50 \mathrm{mg} \mathrm{L}^{-1}$ ascorbic acid, $100 \mathrm{mg} \mathrm{L}^{-1} \mathrm{AC}, 3 \%$ sucrose/table sugar, and $0.8 \%$ agar $(\mathrm{w} / \mathrm{v})$ was the optimal shoot multiplication medium.

Concurrent $e x$ vitro rooting and acclimatization In vitro regenerated shoots were rooted ex vitro under greenhouse conditions when pulse-treated with IBA or NAA for different time durations. The frequency of rooting ranged from 35.7 to $90.1 \%$ across the four auxin concentrations tested (Table 3). The overall rooting performance increased with increasing concentration of IBA up to the optimum level of $500 \mathrm{mg} \mathrm{L}^{-1}$ IBA and decreased thereafter. The basal end of the shoots treated with $500 \mathrm{mg} \mathrm{L}^{-1}$ IBA for 5 min proved the best in which $90.1 \%$ of shoots formed the highest number of roots $(8.5 \pm 0.97$ per shoot $)$ with an average length of $9.40 \pm$ $1.06 \mathrm{~cm}$, after $5 \mathrm{wk}$ (Fig. 2e). This is the first report on ex vitro rooting in M. parvifolia. Micro-shoots failed to root ex vitro on the control treatment. Klerk et al. (1995) explained that the auxin pulse treatment improved rooting efficiency in apple cuttings by initiating the first cellular division within 24 to 96-h of the treatment. The efficiency of IBA over other root inducing phytohormones has been well recognized in many species including trees such as Couroupita guianensis (Shekhawat and Manokari 2016), Campomanesia xanthocarpa (Machado et al. 2020), and Picea abies (Zarei et al. 2020).

CEVRA has many advantages over the in vitro rooting: (1) the ex vitro formed roots have root hairs (lateral root system) which make them more effective during transplantation, (2) ex vitro rooting lacks callus formation at the root-shoot junction, (3) the vascular connection between ex vitro formed roots and the shoot is well developed (Bhojwani and Dantu 2013), (4) ex vitro rooting does not require additional acclimatization (an extra step in the in vitro rooting; Panwar et al. 2018), (5) it is economical as it requires less time, labor, and chemicals (Phulwaria et al. 2012). Acclimatization and hardening of regenerated plantlets is a bottleneck factor in transferring micropropagation technology from lab to field conditions. Thus, adoption of the CEVRA technique could be a boon, especially for tree species where rooting, acclimatization, and hardening are major constraints in transplantation. These steps are believed to be the most labor/resource 
Table 3. Influence of Indole-3-butyric acid (IBA) and $\alpha$-Naphthalene acetic acid (NAA) on ex vitro rooting of micropropagated shoots of Mitragyna parvifolia (Roxb.) Korth. (after 5 wk)

\begin{tabular}{llllc}
\hline Auxins $\left(\mathrm{mg} \mathrm{L}^{-1}\right)$ & & $\%$ shoots rooted & Average root number \pm SD & Average root length $(\mathrm{cm}) \pm \mathrm{SD}$ \\
\hline IBA & NAA & & & $0.0 \pm 0.0^{\mathrm{e}}$ \\
\hline Control & - & $0.0^{\mathrm{g}}$ & $0.0 \pm 0.0^{\mathrm{h}}$ & $2.90 \pm 0.77^{\mathrm{d}}$ \\
100 & - & $54.2^{\mathrm{e}}$ & $2.2 \pm 0.63^{\mathrm{f}}$ & $5.39 \pm 0.84^{\mathrm{b}}$ \\
300 & - & $69.0^{\mathrm{c}}$ & $5.3 \pm 0.82^{\mathrm{bc}}$ & $9.40 \pm 1.06^{\mathrm{a}}$ \\
500 & - & $90.1^{\mathrm{a}}$ & $8.5 \pm 0.97^{\mathrm{a}}$ & $5.89 \pm 0.90^{\mathrm{b}}$ \\
700 & - & $75.3^{\mathrm{b}}$ & $6.1 \pm 0.87^{\mathrm{b}}$ & $2.30 \pm 0.68^{\mathrm{d}}$ \\
- & 100 & $35.7^{\mathrm{f}}$ & $1.1 \pm 0.73^{\mathrm{g}}$ & $3.10 \pm 0.75^{\mathrm{d}}$ \\
- & 300 & $54.1^{\mathrm{e}}$ & $3.2 \pm 0.78^{\mathrm{e}}$ & $4.45 \pm 0.83^{\mathrm{c}}$ \\
\hline
\end{tabular}

IBA and NAA pulse treatment duration: 5 min. Means in each column followed by same letters at superscript are not significantly different according to Duncan's Multiple Range Test at $P<0.05$

intensive and determine the eventual success of a clonal propagation. It is estimated that CEVRA can reduce up to 30 to $70 \%$ cost of a micropropagation protocol and maximize the transplant survival rate in the field (Patel et al. 2016b; Panwar et al. 2018).

Soil/field transfer of acclimatized plantlets The CEVRA plantlets $(10$ to $12 \mathrm{~cm})$ obtained from all the rooting experiments were transplanted to the earthen pots containing a mixture of sand, garden soil, and farmyard manure (1:1:1) and kept in the greenhouse near the fan section for the next 2 to 3 wk (Fig. 2f). CEVRA facilitated the plantlets to develop their phototrophic growth by enhancing leaf size, thickness, and cuticle development. Afterwards, successfully hardened plants with more than $80 \%$ transplant survival rate were transferred to the nursery and subsequently to the field. The micropropagated plants exhibited normal morphology and growth characteristics that are phenotypically analogous to the mother plant.

\section{Conclusions}

A simple, efficient, and repeatable micropropagation protocol using mature nodal explants of Mitragyna parvifolia, an endangered and pharmaceutically important tree of the Indian subcontinent, has been developed. This protocol is improvised over the earlier report (Roy et al. 1988) by standardizing the seasonal and micro-environmental factors influencing in vitro propagation such as removing branches (lopping) of mother plant, season of explant collection, media types and their strengths, recurrent transfer of mother explants, PGRs, additives, activated charcoal, and gelling agents. This is the first report on concurrent ex vitro rooting and acclimatization
(CEVRA) of M. parvifolia which made this protocol economically favorable for the ex situ conservation and for providing the raw material for extraction of numerous significant alkaloids.

Funding information The authors are grateful to the Department of Biotechnology (DBT), Government of India, for providing financial assistance towards establishing Micropropagation and Hardening Unit at Department of Botany, Jai Narain Vyas University, Jodhpur.

\section{References}

Agarwal T, Gupta AK, Patel AK, Shekhawat NS (2015) Micropropagation and validation of genetic homogeneity of Alhagi maurorum using SCoT, ISSR and RAPD markers. Plant Cell Tiss Org Cult 120:313-323

Bhandari MM (1995) Flora of the Indian Desert. In: MPS Repros, Jodhpur, India

Bhojwani SS, Dantu PK (2013) Plant tissue culture: an introductory text. Springer, New York

Bidalia A, Hanief M, Rao KS (2017) Tolerance of Mitragyna parvifolia (Roxb.) Korth. seedlings to $\mathrm{NaCl}$ salinity. Photosynthetica 55:231239

Brown PN, Lund JA, Murch SJ (2017) A botanical, phytochemical and ethnomedicinal review of the genus Mitragyna korth: implications for products sold as kratom. J Ethnopharmacol 202:302-325

Catalogue of Life (2020) Indexing the world's known species. http:// www.catalogueoflife.org/col/details/species/id/ 6c6b257bd673dfc2e2c9d78ea0256c88. Accessed on April 8, 2020

Chatterjee A, Dhara KP, Banerji J (1982) Alkaloids of Mitragyna parvifolia (Roxb) Korth. and their transformations. J Indian Chem Soc 59:1360-1363

Chhajer S, Kalia RK (2017) Seasonal and micro-environmental factors controlling clonal propagation of mature trees of marwar teak 
[Tecomella undulata (Sm.) Seem]. Acta Physiol Plant 39(1-15):60. https://doi.org/10.1007/s11738-017-2364-2

Funada R, Kubo T, Tabuchi M, Sugiyama T, Fushitani M (2001) Seasonal variations in endogenous indole-3-acetic acid and abscisic acid in the cambial region of Pinus densiflora Sieb. et Zucc. stems in relation to earlywood/latewood transition and cessation of tracheid production. Holzforschung 55:128-134

Govaerts R, Ruhsam M, Andersson L, Robbrecht E, Bridson D, Davis A, Schanzer I, Sonké B (2015) World checklist of Rubiaceae. The Board of Trustees of the Royal Botanic Gardens, Kew. Published online: http://www.kew.org/wcsp/rubiaceae/. Accessed May 6, 2015

Greenwell ZL, Ruter JM (2018) Effect of glutamine and arginine on growth of Hibiscus moscheutos "in vitro". Ornam Hortic 24:393399

Gupta S, Kachhwaha S, Kothari SL, Jain R (2020) Synergistic effect of cytokinins and auxins enables mass clonal multiplication of drumstick tree (Moringa oleifera Lam.): a wonder. In Vitro Cell Dev Biol-Plant. https://doi.org/10.1007/s11627-020-10065-0

Hassan Z, Muzaimi M, Navaratnam V, Yusoff NH, Suhaimi FW, Vadivelu R, Vicknasingam BK, Amato D, von Hörsten S, Ismail NI, Jayabalan N, Hazim AI, Mansor SM, Muller CP (2013) From Kratom to mitragynine and its derivatives: physiological and behavioural effects related to use, abuse, and addiction. Neurosci Biobehav Rev 37:138-151

Huang H, Wei Y, Zhai Y, Ouyang K, Chen X, Bai L (2020) High frequency regeneration of plants via callus-mediated organogenesis from cotyledon and hypocotyl cultures in a multipurpose tropical tree (Neolamarkia cadamba). Sci Rep 10(1-10):4558. https://doi. org/10.1038/s41598-020-61612-Z

Klerk GJD, Keppel M, Brugge JT, Meekes H (1995) Timing of the phases in adventitous root formation in apple microcuttings. J Exp Bot 46:965-972

Liu Y, Lu J, Zhu H, Li L, Shi Y, Yin X (2016) Efficient culture protocol for plant regeneration from cotyledonary petiole explants of Jatropha curcas L. Biotechnol Biotechnol Equip 30:907-914

Lloyd G, McCown B (1981) Commercially feasible micropropagation of mountain Laurel Kalmia latifolia by use of shoot tip culture. Proc Intl Plant Prop Soc 30:421-427

Machado JS, Degenhardt J, Maia FR, Quoirin M (2020) Micropropagation of Campomanesia xanthocarpa O. Berg (Myrtaceae), a medicinal tree from the Brazilian Atlantic forest. Trees. https://doi.org/10.1007/s00468-020-01958-z

Middleton BA (2009) Vegetation status of the Keoladeo National Park, Bharatpur, Rajasthan, India (April 2009). US Geological Survey Science Investigation Report 5193 pp. 5193-5200. U.S. Geological Survey, Reston 2009

Murashige T, Skoog F (1962) A revised medium for rapid growth and bioassays with tobacco tissue cultures. Physiol Plant 15:473-497

Pandey R, Singh SC, Gupta MM (2006) Heteroyohimbinoid type oxindole alkaloids from Mitragyna parvifolia. Phytochemistry 67: 2164-2169

Panwar J, Tarafdar JC (2006) Distribution of three endangered medicinal plant species and their colonization with arbuscular mycorrhizal fungi. J Arid Environ 65:337-350

Panwar D, Patel AK, Shekhawat NS (2018) An improvised shoot amplification and ex vitro rooting method for offsite propagation of Tinospora cordifolia (Willd.) Miers: a multi-valued medicinal climber. Ind J Plant Physiol 23:169-178

Patel AK, Ram K, Shekhawat NS (2016a) In vitro propagation and ex vitro rooting of Mitragyna parvifolia (Roxb.) Korth.: a threatened tree of medicinal values. In Vitro Cell Dev Biol—Plant. https://doi. org/10.1007/s11627-016-9771-8

Patel AK, Lodha D, Ram K, Shekhawat S, Shekhawat NS (2016b) Evaluation of physiochemical factors affecting high frequency plant regeneration of Blyttia spiralis (Forssk.) D.V. Field \& J.R.I. wood [synonym: Pentatropis spiralis (Forssk.) Decne.], a threatened climber of medicinal values. In Vitro Cell Dev Biol-Plant 52:10 19

Phongprueksapattana S, Putalun W, Keawpradub N, Wungsintaweekul J (2008) Mitragyna speciosa: hairy root culture for triterpenoid production and high yield of mitragynine by regenerated plants. Z Naturforsch C J Biosci 63:691-698

Phulwaria M, Ram K, Gahlot P, Shekhawat NS (2011) Micropropagation of Salvadora persica-a tree of arid horticulture and forestry. New For 42:317-327

Phulwaria M, Rai MK, Harish GAK, Ram K, Shekhawat NS (2012) An improved micropropagation of Terminalia bellirica from nodal explants of mature tree. Acta Physiol Plant 34:299-305

Phulwaria M, Patel AK, Rathore JS, Ram K, Shekhawat NS (2014) An improved micropropagation and assessment of genetic stability of micropropagated Salvadora oleoides using RAPD and ISSR markers. Acta Physiol Plant 36:1115-1122

Raffa RB (2015) Kratom and other mitragynines: the chemistry and pharmacology of opiods from a non-opium source. CRC Press, Boca Raton

Rai PK, Lalramnghinglova H (2011) Ethnomedicinal plants of India with special reference to an Indo-Burma hotspot region: an overview. Ethnobot Res Appl 9:379-420

Roy SK, Rahman Sk L, Datta PC (1988) In vitro propagation of Mitragyna parvifolia Korth. Plant Cell Tiss Org Cult 12:75-80

Sharma S, Venkatasalam EP, Patial R, Latawa J, Singh S (2011) Influence of gelling agents and nodes on the growth of potato microplant. Potato J 38:41-46

Shekhawat MS, Manokari M (2016) In vitro propagation, micromorphological studies and ex vitro rooting of cannon ball tree (Couroupita guianensis aubl.): a multipurpose threatened species. Physiol Mol Biol Plants 22:131-142

Shekhawat NS, Mohnot S, Phulwaria M, Harish SS (2012) Micropropagation of Salvadora oleoides - an oil yielding tree of arid forests. J Sustain For 31:620-632

Shellard EJ, Houghton PJ (1971) The Mitragyna species of Asia. Part XIX. The alkaloidal pattern in Mitragyna parvifolia (Roxb.) Korth. Planta Med 20:82-89

Shellard EJ, Lala PK (1977) The Mitragyna species of Asia. Part XXIX. The alkaloidal pattern in the leaves, stem bark and root bark of Mitragyna parvifolia from the Kerala state, India. Planta Med 31: 395-399

Shellard EJ, Phillipson JD, Gupta D (1969) The Mitragyna species of Asia. Part XV. The alkaloids from the bark of Mitragyna parvifolia (Roxb.) Korth and a possible biogenetic route for the oxindole alkaloids. Planta Med 17:146-163

Sivanandhan G, Selvaraj N, Ganapathi A, Manickavasagam M (2015) Effect of nitrogen and carbon sources on in vitro shoot multiplication, root induction and withanolides content in Withania somnifera (L.) Dunal. Acta Physiol Plant 37(1-10):12. https://doi.org/10.1007/ s11738-014-1758-7

Su YH, Liu YB, Zhang XS (2011) Auxin-cytokinin interaction regulates meristem development. Mol Plant 4:616-625

The Wealth of India (1998) Council for Scientific and Industrial Research (CSIR), Vol 6. New Delhi

Thomas TD (2008) The role of activated charcoal in plant tissue culture. Biotechnol Adv 26:618-631

UNESCO-IUCN Enhancing Our Heritage Project (2003) Monitoring and managing for success in natural world heritage sites; initial management effectiveness evaluation report. Keoladeo National Park, Bharatpur, pp 1-69

Werden LK, Sugii NC, Weisenberger L, Keir MJ, Koob G, Zahawi RA (2020) Ex situ conservation of threatened plant species in island biodiversity hotspots: a case study from Hawaii. Biol Conserv $243: 108435$ 
Zarei M, Salehi H, Jowkar A (2020) Controlling the barriers of cloning mature Picea abies (L.) H. Karst. via tissue culture and cocultivation with Agrobacterium rhizogenes. Trees. https://oi.org/ 10.1007/s00468-019-01945-z

Ziv M (1991) Vitrification: morphological and physiological disorders of in vitro plants. In: Debergh PC, Zimmerman RH (eds) Micropropagation: technology and application. Kluwer, Dordrecht

Zuldin NNM, Said IM, Noor NM, Zainal Z, Kiat CJ, Ismail I (2013) Induction and analysis of the alkaloid mitragynine content of a Mitragyna speciosa suspension culture system upon elicitation and precursor feeding. Sci World J 2013(1-11):209434 